\title{
Raynaud's phenomenon and positive antinuclear antibodies in a malignancy
}

\author{
Carles Tolosa-Vilella, Josep Ordi-Ros, Miquel Vilardell-Tarres, Albert Selva-O'Callaghan, \\ Rosa Jordana-Comajuncosa
}

\begin{abstract}
Both Raynaud's phenomenon and the presence of antinuclear antibodies are uncommon features of malignant disease and the association of both with a malignancy extremely rare. The case is reported of a 78 year old woman who presented with Raynaud's phenomenon and positive antinuclear antibodies related to adenocarcinoma of unknown primary site.
\end{abstract}

Raynaud's phenomenon is a vascular disorder characterised by episodes of abnormal digital vasospasm in the hands and sometimes in the feet. These episodes occur in response to cold or emotional stress and produce one or more colour changes. The most common sequence is an initial pallor followed by cyanosis and rubor, but incomplete episodes are more common. ${ }^{1}$ The prevalence in the general population has been estimated as 4-10\%. ${ }^{2}$ Raynaud's phenomenon as an isolated condition is classified as primary, and secondary when an underlying cause can be identified. ${ }^{1}$ The presence of antinuclear antibodies in these patients was often associated with connective tissue diseases ${ }^{3}$ and only in rare cases with malignancies. ${ }^{4} \mathrm{We}$ report a patient with Raynaud's phenomenon and a high antinuclear antibody titre related to neoplasia.

\section{Case report}

A 78 year old woman presented with a two month history of gradual loss of weight and episodes of coldness, pallor and paraesthesia in all fingers of her hands followed by rubor with warming. She denied tâking any drugs or smoking and did not have any signs or symptoms suggestive of connective tissue disease. On examination she looked well. Her fingers were not affected and the peripheral pulses were all palpable. There was no evidence of a cervical rib or carpal tunnel. Blood pressure was 140/70 $\mathrm{mmHg}$. The rest of the clinical examination was unremarkable.

Laboratory tests showed white blood cell count $7 \cdot 8 \times 10^{9} / 1$, haemoglobin $149 \mathrm{~g} / \mathrm{l}$, platelet count $282 \times 10^{9} / 1$, erythrocyte sedimentation rate $13 \mathrm{~mm} / \mathrm{h}$, total protein $64.1 \mathrm{~g} / \mathrm{l}$, gammaglobulin $8.8 \mathrm{~g} / \mathrm{l}$, alkaline phosphatase $137 \mathrm{IU}$ (normal <92). Results of urine analysis, complement profile, hepatitis B surface antigen, smooth muscle, antimitochondrial and anticentromere antibodies, cryoglobulins, cold agglutinins, rheumatoid factor, and screening test for syphilis were all normal or negative. The test for antinuclear antibodies was positive with a titre of $1 / 2560$ in a speckled pattern. An ultrasonographic study of the abdomen disclosed several hyperechogenic areas within the liver. A percutaneous needle biopsy was carried out and microscopical examination showed infiltration by moderately differentiated adenocarcinoma. Her primary malignant disease remained undiagnosed despite further examinations. Treatment was suggested for her symptoms and the patient was discharged; her Raynaud's phenomenon did not worsen. She died four months later. A necropsy was not allowed.

\section{Discussion}

Raynaud's phenomenon is generally classified as primary when no associated condition explains its presence and secondary when accompanied by one of several disorders. ${ }^{1}$ Raynaud's phenomenon secondary to neoplasia has rarely been reported, ${ }^{4-8}$ except when related to chemotherapeutic treatment. ${ }^{9}$ The most common histological variant found was adenocarcinoma, usually in an advanced stage. The vascular symptoms may be poor, as in our patient, but typically onset is acute, bilateral with persistent ischaemic manifestations that often progress to digital necrosis. ${ }^{4-8}$ Sometimes Raynaud's phenomenon may improve after tumour treatment. $^{78}$

The presence of antinuclear antibodies is common in connective tissue diseases, but they have been associated with malignancies, also. Moreover, it has been suggested that malignant disease should be suspected in patients with a positive antinuclear antibody test in whom there is no evidence of connective tissue disease or drugs taken associated with antinuclear antibody induction. ${ }^{10-12}$ These antibodies are probably an epiphenomenon and are usually detected in a low titre. ${ }^{4} 12$ The speckled pattern found in the case reported here has often been found associated with malignancies and it seems to be related to novel specific antigenic determinants. ${ }^{413}$

The association of Raynaud's phenomenon and a positive antinuclear antibody test is common in connective tissue diseases, such as scleroderma and systemic lupus erythematosus, but extremely rare in malignant diseases. ${ }^{4}$

In this patient, with metastatic adenocarcinoma of unknown primary site, there was no evidence of any signs or symptoms of aetiological factors that might explain the 
presence of antinuclear antibodies and Raynaud's phenomenon. Thus we believe that these features were both related to her malignant disease. Thus the possibility of a malignancy should be borne in mind when there is sudden development of Raynaud's phenomenon or a positive antinuclear antibody test, or both, in the absence of any other disorder.

1 Campbell P M, LeRoy E C. Raynaud phenomenon. Semin Arthritis Rheum 1986; 16: 92-103.

2 Maricq H R, Weinrich M C, Keil J E, LeRoy E C. Prevalence of Raynaud phenomenon in the general population [Abstract]. Arthritis Rheum 1984; 27: S18.

3 Kallenberg C G M, Wouda A A, Hoet M H, Venrooij W J V. Development of connective tissue disease in patients presenting with Raynaud phenomenon: a six year follow up with emphasis on the predictive value of antinuclear antibodies as detected by immunoblotting. Ann Rheum Dis 1988; 47: 634-41.

4 Freundlich B, Makover D, Maul G G. A novel antinuclear antibody associated with a lupus-like paraneoplastic syndrome. Ann Intern Med 1988; 109: 295-7.

5 Hawley $\mathbf{P}$ R; Johnston A W, Rankin J T. Association between digital ischaemia and malignant disease. $\mathrm{Br} M e d \mathcal{J}$ 1967; iii: 208-12.

6 Vilmalaratna H S K, Sachdev D. Adenocarcinoma of the lung presenting with Raynaud's phenomenon, digital gangrene Rheumatol 1987; 26: 473-5.

7 Andrasch R H, Bardana E J, Porter J M, Pirofsky B. Digital ischaemia and gangrene preceding renal neoplasm. Arch ischaemia and gangrene precedi

8 Field J, Lane I F. Carcinoma of the lung presenting with digital ischaemia. Thorax 1986; 41: 573-4.

9 Vogelzang N J, Bosl G J, Johnson K, Kennedy B J. Raynaud's phenomenon: a common toxicity after combination chemotherapy for testicular cancer. Ann Intern Med 1981; 95: 288-92.

10 Zeromski J O, Gorny M K, Jarczewska K. Malignancy associated with antinuclear antibodies. Lancet 1972; ii: 1035-6.

11 Burnham T K. Antinuclear antibodies in patients with malienancies. Lancet 1972; ii: 436-7.

12 Ablin R J. Malignancy associated with antinuclear antibodies. Lancet 1972; ii: $1253-4$.

13 Wallach $H$ W. Lupus-like syndrome associated with carcinoma of the breast. Arch Intern Med 1977; 137: 532-5. 